\title{
The Study on the Substrate Effect in the Nanoindentation Experiment of the Hybrid Material
}

\author{
Kang Liang, ${ }^{1,2}$ Kunpeng Gao $\mathbb{D}^{1}{ }^{1}$ and Wenqing $\mathrm{Cai}^{2}$ \\ ${ }^{1}$ Nanjing Vocational University of Industry Technology, Nanjing 210023, China \\ ${ }^{2}$ Tongji University, Shanghai 200092, China \\ Correspondence should be addressed to Kunpeng Gao; gao.kunpeng@foxmail.com
}

Received 2 November 2021; Accepted 14 December 2021; Published 4 January 2022

Academic Editor: Gaofeng Song

Copyright (c) 2022 Kang Liang et al. This is an open access article distributed under the Creative Commons Attribution License, which permits unrestricted use, distribution, and reproduction in any medium, provided the original work is properly cited.

The nanoindentation (NI) experiment is an effective method to evaluate the micromechanical property of materials. The substrate effect is a nonnegligible factor which could influence the accuracy of the NI experiment result. Large numbers of previous studies have focused on the substrate effect based on the coating/substrate model, whereas the substrate effect in the testing of the hybrid material was rarely involved. The real NI experiment and the numerical simulation method were adopted to reveal the characteristics of the substrate effect in the NI experiment of the hybrid material in this paper, such as the rock or cement material. The peak displacement $h_{\text {peak }}$ and the residual displacement $h_{\text {residual }}$ of the indenter, which could obtain directly from the NI experiment and were usually considered as key basic variables to calculated other parameters, were selected as evaluation indexes of the substrate effect. The results indicated that there was a significant difference of the NI experiment result between the coating/ substrate and the hybrid material under the same condition. The lateral boundary stiffness and discontinuous face were considered as main factors that induced this difference, and their effect were analysed, respectively. Young's modulus $E_{s}$ and Poisson's ratio $\mu_{s}$ of the substrate were selected as the variables in the parametric study, and the relationship between them and the NI experiment result were discussed.

\section{Introduction}

The nanoindentation experiment (NI experiment) is one of the most powerful techniques for evaluating the micromechanical behaviour of materials related to the mining engineering, such as the rock or the cement material [1-8]. This method records the applied load and the indentation depth during the indenter contacting the target object, such as the thin films and the small volumes of materials, and then the hardness, the elastic modulus, and other mechanical parameters of the material could be computed based on the Oliver-Pharr's method or other methods.

However, the substrate effect is a nonnegligible factor which could seriously affect the NI experiment accuracy [2, 5, 9-17]. For instance, this effect was dramatically shown in one of our experiments. During this experiment, the indentation depths of unhydrated cement granular were extremely different in various substrate materials in the same experiment conditions (the indenter, loading, etc.). The indentation depths in different substrate materials ranged from 71 to $500 \mathrm{~nm}$ under $1 \mathrm{mN}$ load. The detail of this experiment was introduced in Section 2.

This huge difference reveals the dramatically substrate effect in the NI experiment, and some studies have already focused on this inevitable influence of the substrate. Various potentially relevant factors have been selected as study objects. The indentation depth is considered as a directly factor which is closely related to substrate effect, because the indentation depth could be obtained in NI experiment directly $[3,13,18]$. As a rule of thumb, deep indentation depth could induce strong substrate effect, and the substrate effect could be ignored when the relative indentation depth (RID, the penetration divided by the coating thickness) is less than $0.1[3,13]$. This RID value is not stringent enough under different coating/substrate combinations, indenter shape, indenter size, surface roughness, and so on $[3,13,19,20]$. 
The yield stress and the elastic modulus ratio between the coating and substrate, that is, $E_{c} / E_{s}$, are considered as prime parameters, which could influence the RID values $[13,15]$. When $\sigma_{y c} / \sigma_{y s}<10$, the RID $<10 \%$ could be applicable, and RID value should be less than $5 \%$ when $\sigma_{y c} / \sigma_{y s} \geq 10$ and $E_{c} / E_{s}>0.1[15]$.

Previous studies have obtained profound comprehension of substrate effect; however, accurate evaluation of substrate effect in the hybrid material, that is, the rock or the cement material, is still a challenging task. The previous studies mainly focused on coating/substrate model, in which the testing object (coating) covers the substrate material. This model could be credible in laminated composites or coating materials, but it should not be suited in the hybrid material. In the hybrid material, the testing object is usually embedded in the mixed material, and the mechanic response is inevitably influenced by surrounding materials.

This paper aimed to gain an in-depth understanding of the substrate effect in the NI experiment of the hybrid material. The basic mechanical properties (Young's modulus and Poisson's ratio) of substrate, which were usually considered as prime effect factors $[13,15]$, were selected as study parameters, and the numerical simulation method was selected. With 27 groups of numerical experiments, the substrate properties' influence in hybrid material on the NI experiment was illustrated by analysing the peak displacement $\left(h_{\text {peak }}\right)$ and residual displacement $\left(h_{\text {residual }}\right)$ of the indenter under the same loading, which were usually considered as key direct data of NI experiment results $[3,10,19,21,22]$.

\section{Experiment}

To reveal the substrate effect in the hybrid material, a series of experiments were conducted with the NI technology. The hybrid material was selected as the hardening cement, and the tested object was selected as the unhydrated cement granular, which was unavoidable and existed in the hardening cement. Besides, an epoxy resin sample, which contained unhydrated cement granular, was also conducted as the limiting case.

The hardening cement was made up of the Portland cement P.II 42.5 in this experiment, and its chemical constitutions are listed in Table 1. The water-cement ratio of cement was set as 0.4 in all cement samples. The adhesive strength of epoxy resin is $6 \mathrm{Mpa}$. The detailed test process is as follows.

2.1. The Sample preparation. The epoxy sample is prepared as follows. The cement particles greater than $80 \mu \mathrm{m}$ were selected using cement sifter and then dealt with the drying oven for 2 hours at $105^{\circ} \mathrm{C}$. The dried selected cement particles were mixed with epoxy resin on a mass ratio of $3: 1$ and then curing this mixture for 10 days before test.

The cement samples are prepared as follows. The cement with a water-to-cement ratio of 0.4 was cast into cylinder specimens (10 $\mathrm{mm}$ diameter) and then was cured in a sealed and saturated moisture environment at $20 \pm 2^{\circ} \mathrm{C}$ for 1 day, 28 days, and 60 days, respectively.
2.2. Polishing Procedures. Firstly, samples used in this experiment were cut to $10 \mathrm{~mm}$ height. Secondly, samples were polished on silicon carbide papers down till 4000 grades and then polished using charoset or flannel polishing pad to obtain a smooth surface at both ends. The tilt angle of two ends of planes is less than on degree, measured by vernier. The ethanol is used to clean the samples during polishing process.

2.3. Experimental Methods. The type of indenter adopted the common Berkovich indenter in all experiments. The NI depth and load were recorded during the test. The maximum load is set as $1 \mathrm{Mn}\left(P_{\max }=1 \mathrm{mN}\right)$, and the loading shape is set as trapezoidal defined by $10 \mathrm{~s}$ loading time, $5 \mathrm{~s}$ holding time, and $10 \mathrm{~s}$ unloading time.

Following the experiment procedure mentioned above, the typical load-depth curves for respective test conditions are shown in Figure 1. Two key points of curves were selected as study indicators: the peak depth $h_{\text {peak }}$ (peak indenter displacement) and the residual displacement $h_{\text {residual }}$ of indenter after unloading. This is because $h_{\text {peak }}$ and $h_{\text {residual }}$ were generally considered as the key parameters, which could be obtained directly in the NI experiment, to calculate mechanical parameters of material according to OliverPharr's model or other methods. In other words, $h_{\text {peak }}$ and $h_{\text {residual }}$ would differ under different substrates if the substrate effect existed under the same loading.

The strength of various substrates and the corresponding NI results is presented in Table 2. The strength of cement cases referred to the compressive strength, and the bonding strength was used in the epoxy resin case.

The results show the peak indenter displacement in tests ranges from 71 to $94 \mathrm{~nm}$ in substrate of cement and more than $500 \mathrm{~nm}$ in substrate of epoxy resin. The substrate's property has a significant effect on the test result. The higher the strength of the substrate, the smaller the peak indenter displacement at the same peaking load. In other words, the softer substrate results in higher peak indenter displacement. The residual displacement has more complex relationship with the substrate strength. When the substrate strength is lower (i.e., epoxy resin), the residual displacement is much greater than the higher strength substrate cases. When the substrate strength increases, the residual displacement becomes smaller and seems to present a fluctuating tendency $(58.60 \mathrm{~nm} \longrightarrow 65.18 \mathrm{~nm} \longrightarrow 30.88 \mathrm{~nm})$. It could be referred that the overall relationship between the residual displacement and the strength is negative correlation, but when the strength is relatively higher, fluctuation will appear.

\section{Numerical Simulation}

The conclusion, which has been obtained in Section 2, is relatively rough and unconvincing limiting to the NI experiment number. To obtain a clear understanding of the substrate effect in the hybrid material, numerical investigations were conducted with FEM by considering various substrates with different Young's modules and Poisson's rations in numerical models of the hybrid material or 
TABle 1: Chemical compositions of cement (in mass percent).

\begin{tabular}{lcccccccccc}
\hline $\mathrm{Na}_{2} \mathrm{O}$ & $\mathrm{MgO}$ & $\mathrm{Al}_{2} \mathrm{O}$ & $\mathrm{SiO}_{2}$ & $\mathrm{SO}_{3}$ & $\mathrm{~K}_{2} \mathrm{O}$ & $\mathrm{CaO}$ & $\mathrm{TiO}_{2}$ & $\mathrm{MnO}_{2}$ & $\mathrm{Fe}_{2} \mathrm{O}_{3}$ & $\mathrm{SrO}$ \\
\hline 0.29 & 1.09 & 3.91 & 21.4 & 1.85 & 0.64 & 66.5 & 0.18 & 0.08 & 2.75 & 0.06 \\
\hline
\end{tabular}

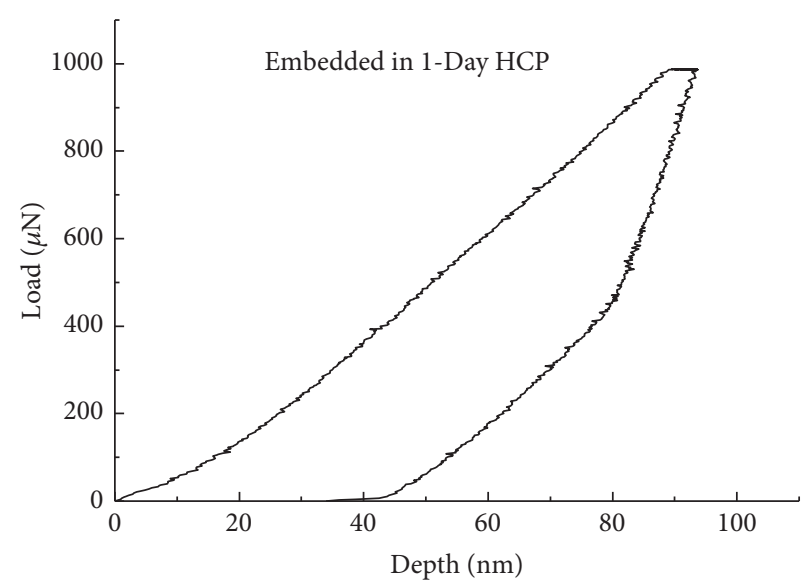

(a)

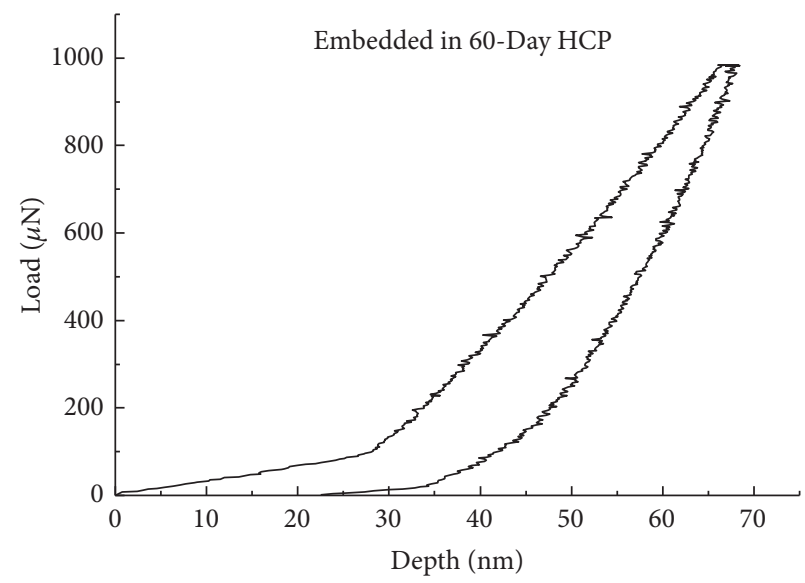

(c)

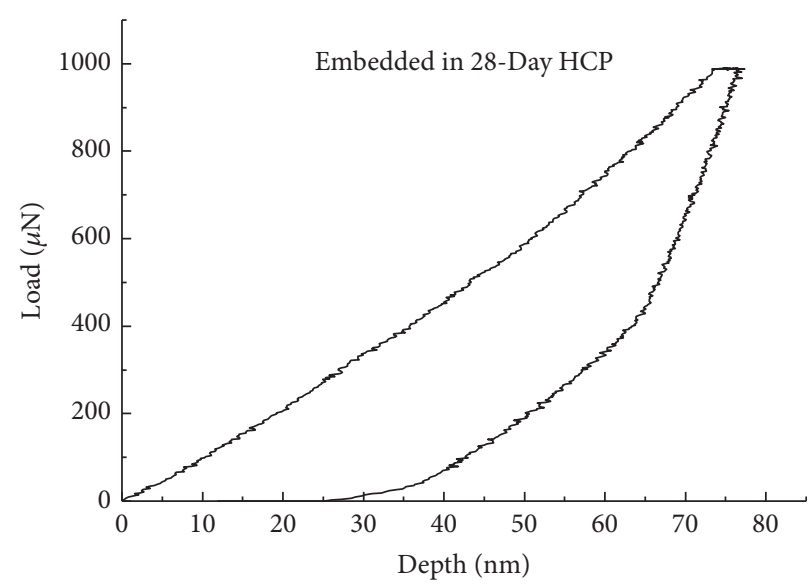

(b)

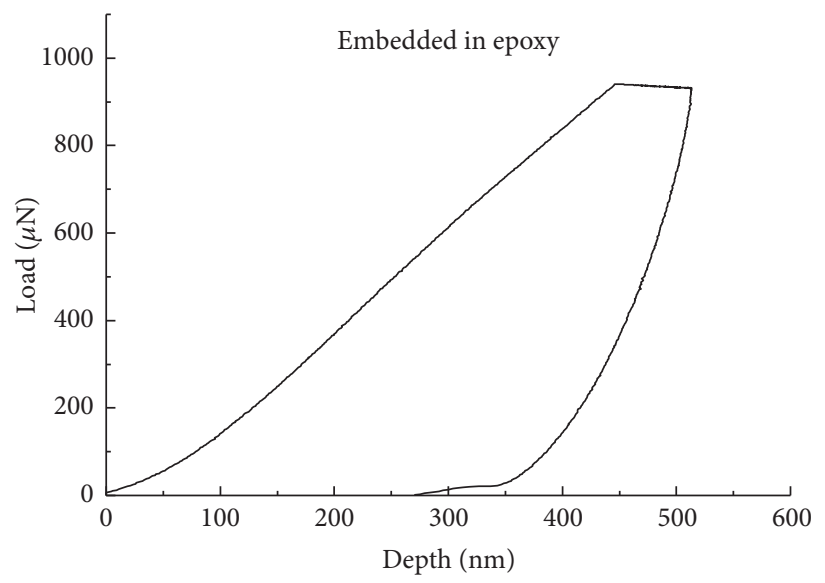

(d)

Figure 1: Typical load-depth curves of cement particles.

TABLE 2: NI results of cement particles under different embedded conditions.

\begin{tabular}{lcccc}
\hline Embedded condition & 1-day HCP & 28-day HCP & 60-day HCP & Epoxy resin \\
\hline Strength $(\mathrm{MPa})$ & 11.44 & 67.73 & 68.54 & 6 \\
$h_{\text {peak }}(\mathrm{nm})$ & 94.38 & 93.14 & 71.83 & 589.14 \\
$h_{\text {residual }}(\mathrm{nm})$ & 58.60 & 65.18 & 30.88 & 424.21 \\
\hline
\end{tabular}

coating/substrate combination, respectively. As a widely used method, the FEM method could well reflect the deformation and mechanical law of various type of materials and structure, with lower economic and time costing. In this paper, a general-purpose FEM package ABAQUS was used.

The substrate effect was reflected by the difference of indentation depth $\left(h_{\text {peak }}\right.$ and $\left.h_{\text {residual }}\right)$ under the same load $[12,15]$. Three series of numerical experiments were designed to investigate substrate effect on the NI experiment, as shown in Table 3. Series 1 and series 2 focused on the influence of Young's modules and Poisson's rations of the substrate in the hybrid material. Series 3 considered to reveal the difference between the hybrid material and the coating/ substrate combination using a coating/substrate model.

A simplified plane model, using the necessary axial symmetry conditions, was adopted, in both the model of the hybrid material and coating/substrate combination, to avoid long time costing and decrease convergence difficulties $[3,11,15,19$, 21, 23, 24]. Previous studies show that the result difference between the 2D model and 3D model is within a few percent in the nanoindentation simulation, and this simplification usually has an accurately indication of the reality [13].

The analysis domain consisted of three parts, the indenter, the testing material, and the substrate (see Figure 2). 
TABLE 3: Design of the numerical experiment and computation results.

\begin{tabular}{|c|c|c|c|c|c|}
\hline \multirow{2}{*}{ Series } & \multirow{2}{*}{ Case } & \multicolumn{2}{|c|}{ Substrate } & \multirow{2}{*}{$h_{\text {peak }}(\mathrm{nm})$} & \multirow{2}{*}{$h_{\text {residual }}(\mathrm{nm})$} \\
\hline & & $E_{s}(\mathrm{GPa})$ & $\mu_{s}$ & & \\
\hline \multirow{19}{*}{1 (the hybrid material model) } & a1 & 1 & 0.2 & 1257.99 & 218.67 \\
\hline & $\mathrm{a} 2$ & 2 & 0.2 & 735.36 & 174.80 \\
\hline & a3 & 3 & 0.2 & 556.39 & 167.40 \\
\hline & $\mathrm{a} 4$ & 4 & 0.2 & 465.67 & 159.62 \\
\hline & a5 & 5 & 0.2 & 410.71 & 155.22 \\
\hline & a6 & 6 & 0.2 & 373.81 & 152.45 \\
\hline & a7 & 7 & 0.2 & 347.28 & 150.94 \\
\hline & a8 & 8 & 0.2 & 327.26 & 146.66 \\
\hline & a9 & 9 & 0.2 & 311.91 & $149.94 \uparrow$ \\
\hline & a10 & 10 & 0.2 & 299.05 & $146.08 \downarrow$ \\
\hline & a11 & 20 & 0.2 & 241.55 & $149.59 \uparrow$ \\
\hline & a12 & 30 & 0.2 & 221.86 & 154.30 \\
\hline & a13 & 40 & 0.2 & 211.85 & $153.24 \downarrow$ \\
\hline & a14 & 50 & 0.2 & 205.77 & 157.12 \\
\hline & a15 & 60 & 0.2 & 201.72 & 150.29 \\
\hline & a16 & 70 & 0.2 & 198.81 & $153.45 \uparrow$ \\
\hline & a17 & 80 & 0.2 & 196.61 & 154.91 \\
\hline & a18 & 90 & 0.2 & 194.89 & $153.92 \downarrow$ \\
\hline & a19 & 100 & 0.2 & 193.51 & $156.09 \uparrow$ \\
\hline \multirow{8}{*}{2 (the hybrid material model) } & b1 & 50 & 0.05 & 204.594 & 150.480 \\
\hline & b2 & 50 & 0.10 & 204.999 & 150.649 \\
\hline & b3 & 50 & 0.15 & 205.389 & 155.587 \\
\hline & $\mathrm{b} 4$ & 50 & 0.20 & 205.765 & 157.122 \\
\hline & b5 & 50 & 0.25 & 206.129 & $156.584 \downarrow$ \\
\hline & b6 & 50 & 0.30 & 206.479 & 151.733 \\
\hline & b7 & 50 & 0.35 & 206.815 & $152.096 \uparrow$ \\
\hline & $\mathrm{b} 8$ & 50 & 0.40 & 207.138 & 152.114 \\
\hline \multirow{5}{*}{3 (the coating/substrate model) } & c1 (vs a1) & 1 & 0.2 & 1171.84 & 164.906 \\
\hline & c2 (vs a14) & 50 & 0.2 & 210.702 & 158.043 \\
\hline & c3 (vs a19) & 100 & 0.2 & 197.13 & 158.862 \\
\hline & $\mathrm{c} 4$ (vs b1) & 50 & 0.05 & 210.693 & 158.286 \\
\hline & c5 (vs b8) & 50 & 0.4 & 210.721 & 153.688 \\
\hline
\end{tabular}

In the hybrid material model, the substrate was $30 \mu \mathrm{m} \times 30 \mu \mathrm{m}$, and the testing target was $5 \mu \mathrm{m} \times 5 \mu \mathrm{m}$. In the model of coat/combination, the substrate was $25 \mu \mathrm{m} \times 30 \mu \mathrm{m}$, and the testing target was $5 \mu \mathrm{m} \times 30 \mu \mathrm{m}$. The testing material (or the coating) was assumed to be elastic plastic, with Young's modulus $E_{t}=50 \mathrm{GPa}$, Poisson's ratio $\mu_{t}=0.2$, and plastic yield strength $\sigma_{s}=300 \mathrm{MPa}$. The substrate was assumed to be linearly elastic with different Young's modulus and Poisson's ratio (see Table 3).

Although a Berkovich indenter was used in real tests, previous studies have rarely constructed the indenter model as the Berkovich shape due to the complicated element mesh division and stress concentration. Referring to the relevant literatures $[5,9,11,13,15,21,24]$, the indenter was modeled as a cone with a rounded tip in this paper. The half-included angle of the cone $(\alpha)$ was $70.3^{\circ}$, whereas the tip radius $(R)$ was $100 \mathrm{~nm}$. The indenter was assumed as a rigid body, since otherwise it would be difficult to distinguish the influence of the indenter and the substrate material on the simulation result $[5,11,19,21]$. An investigating point was set on the rigid reference point of indenter, which could monitor the indentation depth and corresponding force. This point could output the force and displacement of indenter of every computing increment in the simulation.

The contact between the indenter and the testing material, and the contact between testing material and substrate were both modeled using the "frictionless" contact option. This option allowed frictionless sliding between two surfaces, and this simplification could satisfy the simulation's accuracy [3]. The bottom boundary of the model was fixed in the vertical direction, and the left side boundary of the model was fixed in the horizontal direction.

The mesh elements near the contact area were refined so that the deformation and stress gradients could be accurately described. The mesh became progressively coarser at distances further away from the main deformation area. The $2 \mathrm{D}$ numerical mesh and boundary conditions are illustrated in Figure 2.

The computation process was divided into two stages. At the first stage, a vertical load of $500 \mu \mathrm{N}$ was gradually applied on the rigid reference point of indenter. During this process, the testing material (or the coating) deformation transferred from elastic to plastic, and the substrate significantly 
deformed correspondingly. With dozens of iterations, a strict equilibrium was achieved. In the second stage, the load which was applied on the rigid reference point was designed to decrease to zero. In this process, the elastic deformation of the system gradually recovered, whereas the plastic deformation was retained.

\section{Results and Discussion}

4.1. Characteristics of the Hybrid Material Substrate Effect. Series 3 and relevant cases of series 1 and 2 (cases a1, a14, $\mathrm{a} 19, \mathrm{~b} 1$, and $\mathrm{b} 8$ ) are selected to be analysed in this section. The substrate's property of cases in series 3 is the same as relevant cases in series 1 and 2, but the numerical model was different. The characteristics of the hybrid material are revealed by contrastive analysing of the difference between them. Through the cases comparison, two conclusions could be observed.

4.1.1. The Difference of the NI Experiment Results. There is a significant difference of experiment results between the hybrid material and the coating/substrate combination when the substrate has a similar property. In the comparative group of $\mathrm{c} 1$ versus al, $h_{\text {peak }}$ and $h_{\text {residual }}$ obtained by the hybrid material model are both bigger than the results obtained by the coating/ substrate combination model, whereas the conclusion is reverse in other comparative groups.

The numerical model's difference between series 3 and relevant cases of series 1 and 2 is mainly the lateral boundary condition of the testing area. In series 3 (coating/substrate combination model), the testing area is actually surrounded by the same material and under the lateral stress derived from the deformation of the same material. In case $\mathrm{cl}$, the lateral stress is derived from the coating material with Young's modulus $E_{t}=50 \mathrm{GPa}$, whereas the lateral stress is provided by the substrate with Young's modulus $E_{s}=1 \mathrm{GPa}$ in the comparative case a1. The low lateral stiffness leads to the bigger strain in the lateral direction and the bigger displacement in the loading direction. As the strength of the substrate increases, the lateral substrate of relevant cases in series 2 and 3 could provide a "harder" boundary than the coating/substrate combination cases in series $3\left(E_{s} \geq 50 \mathrm{GPa}\right.$ in cases a14, a19, b1, and b8), and the indenter displacement is smaller correspondingly in hybrid material models. Only Young's modulus of the substrate $E_{s}$ is considered in the above analysis; that is because Poisson's ratio $\mu_{s}$ has a little effect on the experiment result from series 2 , and the NI experiment result difference mainly comes from Young's modulus in this paper study.

4.1.2. The Characteristic of Stress Distribution. The discontinuous face existed in the model results in the discontinuous of stress distribution and induces stress concentration around the junction of discontinuous faces in the hybrid material model.

In order to reveal the Mises stress distribution pattern around the discontinuous face, 22 measurement points were designed near the interface. The positions of points are shown in Figure 3, and the Mises stress of each point could be seen in Table 4 . Generally speaking, the stress of the testing area is higher than the near position of substrate (the stress difference value is positive), excluding the area of bottom corner of the testing area where the stress concentration occurs. The discontinuous face decreases the stress transfer significantly. Besides that, an interesting finding was revealed. The stress difference between both sides of the discontinuous is generally gradually decreased in the horizontal direction along with the distance to the indenter increasing, whereas it fluctuated in the vertical direction, excluding the area of stress concentration.

\subsection{Effect of Substrate Young's Modulus in the Hybrid} Material. To examine the effect of Young's modulus on the NI experiment, 19 cases with Young's modulus ranging from $1 \mathrm{GPa}$ to $100 \mathrm{GPa}$ were designed and simulated (cases a1-a19). The calculated curves of force versus indentation depth are shown in Figure 4, and the curve shape is similar to the testing result in Section 2. The peak displacement $\left(h_{\text {peak }}\right)$ and the residual displacement $\left(h_{\text {residual }}\right)$ of the indenter were selected as study indicators. $h_{\text {peak }}$ and $h_{\text {residual }}$ of each group are list in Table 3, and the curve of indenter displacement versus substrate Young's modulus is presented in Figure 5.

As shown in Table 3 and Figure 5, the $h_{\text {peak }}$ value varies from $1257.99 \mathrm{~nm}$ to $193.51 \mathrm{~nm}$, with $E_{s}$ increasing from $1 \mathrm{GPa}$ to $100 \mathrm{GPa}$. The decreasing trend of $h_{\text {peak }}$ is markedly different before and after a critical point where $E_{s}$ is approximately equal to $15 \mathrm{GPa}$. Before the critical point, $h_{\text {peak }}$ drops substantially from $1257.99 \mathrm{~nm}$ (case a1) to $299.05 \mathrm{~nm}$ (case a10), with $E_{s}$ just increasing from $1 \mathrm{GPa}$ to $10 \mathrm{GPa}$, only increment of $9 \mathrm{GPa}$, whereas the decreasing value is only $105.54 \mathrm{~nm}$, with $E_{s}$ rising from $10 \mathrm{GPa}$ to $100 \mathrm{GPa}$. The decreasing trend of the curve is significantly slowed down. The bigger $E_{s}$, the smaller decreasing rate. It could be concluded that $h_{\text {peak }}$ will be nearly constant when $E_{s}$ is large enough. In other words, the indentation experiment result has a more sensitive to the lower $E_{s}$.

Furthermore, the residual displacement curve shown in Figure 5 is relatively flatter. The $h_{\text {residual }}$ value varies from $218.67 \mathrm{~nm}$ (maximum value, case a1) to $146.08 \mathrm{~nm}$ (minimum value, case a10), while $E_{s}$ is less than $8 \mathrm{GPa}$ (case a8), and $h_{\text {residual }}$ is decreasing from $218.67 \mathrm{~nm}$ to $146.66 \mathrm{~nm}$, correspondingly. Then, the curve starts to fluctuate with general increasing trend, following $E_{s}$ further increase, but the increment is only $9.43 \mathrm{~nm}$ (compare case a8 to a19). Based on the observation, the relatively lower $E_{s}$ has a nonnegligible impact on $h_{\text {residual }}$, when the plastic property of testing material is considered. The influence of the higher $E_{s}$ is slightly poor regularity but generally enlarges the residual displacement.

The conclusion obtained by numerical experiment is much similar to the phenomenon reflected by experiments in Section 2.

4.3. Effect of Substrate Poisson's Ratio. Eight cases with various $\mu_{s}$ (Poisson's ratio of the substrate) of $0.05,0.1,0.15$, $0.2,0.25,0.3,0.35$, and 0.4 (cases b1-b8) were considered to 


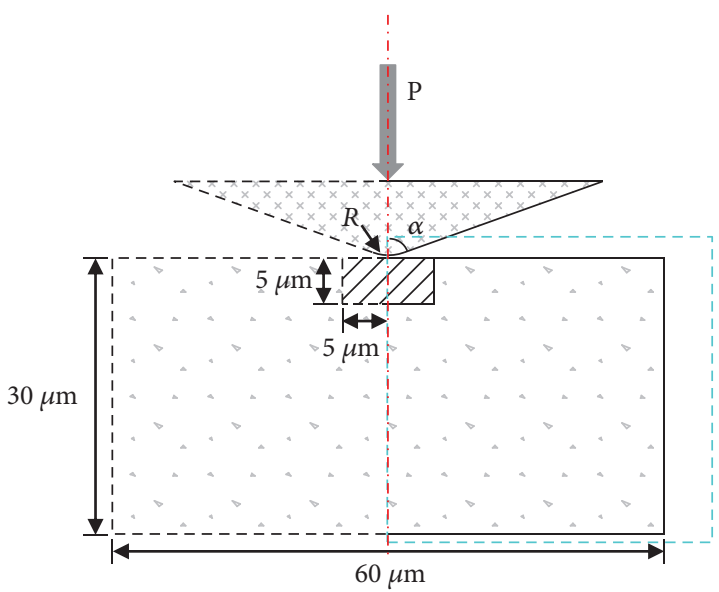

The hybrid material model

(a)

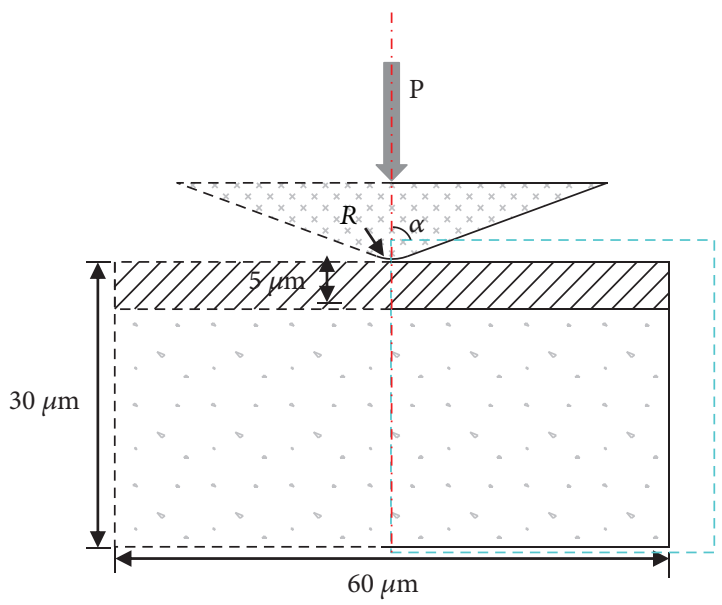

The coating/substrate combination model

(b)

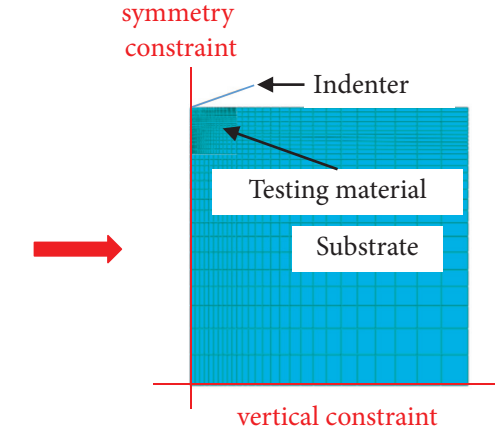

Simplified numerical model

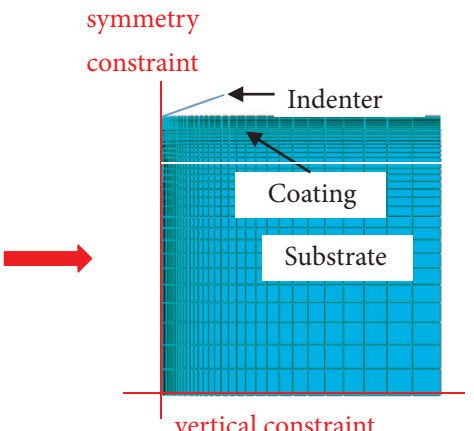

Simplified numerical model

FIgURE 2: Numerical models used in the simulation. $R=100 \mathrm{~nm}$ and $\alpha=70.3^{\circ}$.

examine the effect of Poisson's ratio of the substrate on the NI experiment. $h_{\text {peak }}$ and $h_{\text {residual }}$ for eight cases are compared in Table 3, and the calculated curves of the force versus indentation depth are shown in Figure 6. The relationship between the indenter displacement and $\mu_{s}$ are shown in Figure 7.

It is obvious that with the increasing of $\mu_{s}, h_{\text {peak }}$ increases correspondingly. $h_{\text {peak }}$ has grown from $204.594 \mathrm{~nm}$ to $207.138 \mathrm{~nm}$, along with $\mu_{s}$ increasing from 0.05 to 0.4 . The increment of $2.544 \mathrm{~nm}$ is much less compared with the variation induced by Young's modulus change.

Compared to the positive correlation between $\mu_{s}$ and $h_{\text {peak }}$, the relationship of $\mu_{s}$ and $h_{\text {residual }}$ is relatively complex.
When $\mu_{s}$ is less than 0.2 , the $h_{\text {residual }}$ increases along with $\mu_{s}$ increasing, and the growth rate is rather slow at the initial stage and then grows rapidly but finally slows down, whereas $\mu_{s}$ is bigger than 0.2 , along with $\mu_{s}$ increasing; $h_{\text {residual }}$ decreases slowly firstly, then the descent speed increases, and finally fluctuating rises. It is interesting that the maximum $h_{\text {residual }}$ of eight cases is obtained when the substrate Poisson's ratio $\mu_{s}$ is equal to the testing material, 0.2 in this paper.

Based on the analysis above, it indicates that the sensitivity of the NI experiment results in the substrate Young's modulus $E_{s}$ being much stronger than the substrate Poisson's ratio $\mu_{s}$ in the NI experiment. $h_{\text {residual }}$ is much more influenced by the substrate Poisson's ratio $E_{s}$ than $h_{\text {peak }}$. 


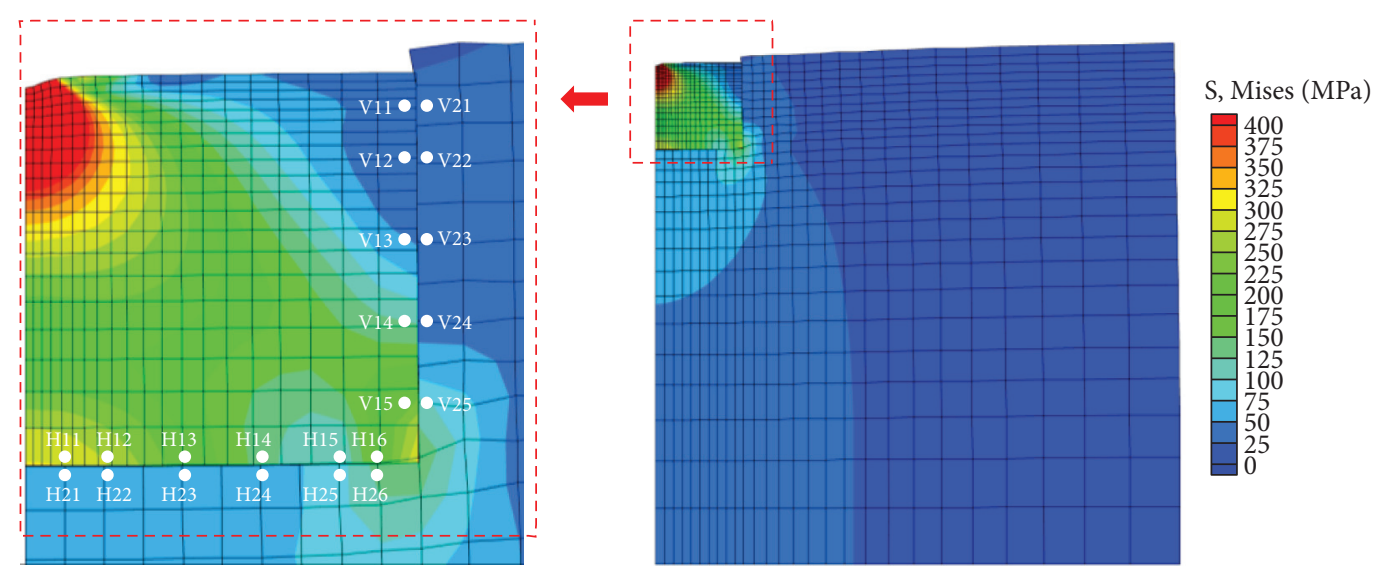

Case a1: $E_{s}=1 \mathrm{GPa}, \mu_{\mathrm{s}}=0.2$.
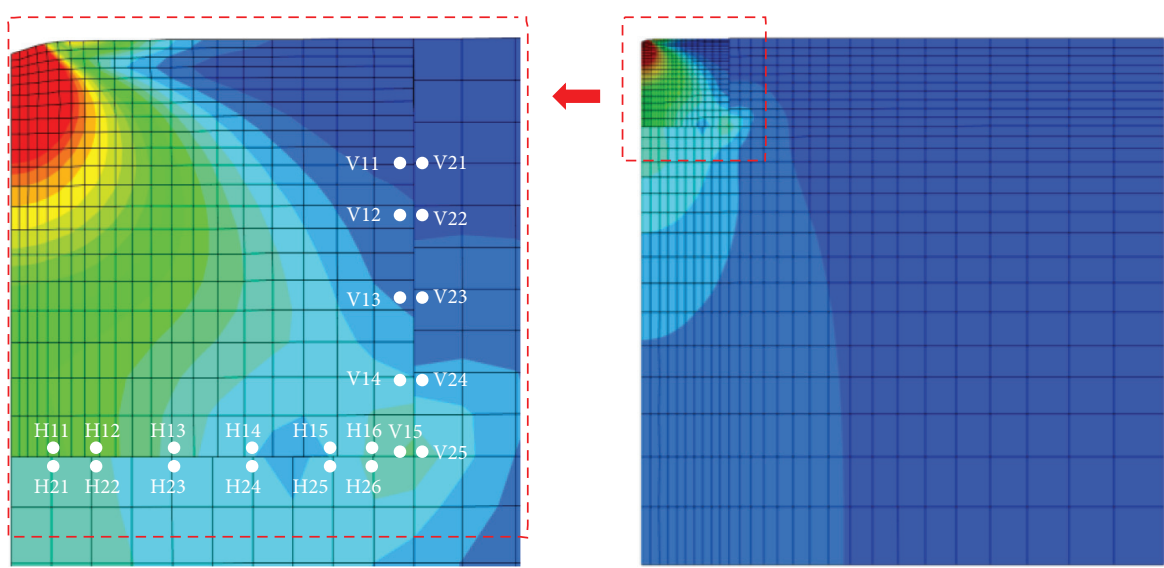

$\mathrm{S}$, Mises (MPa)

Case a14: $E_{s}=50 \mathrm{GPa}, \mu_{\mathrm{s}}=0.2$
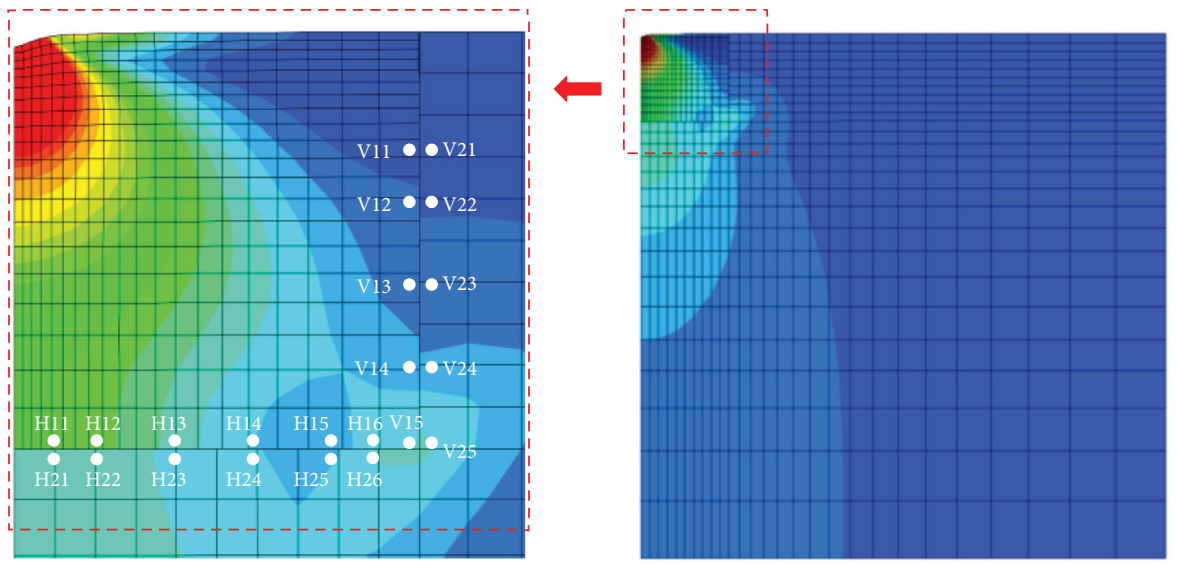

$\mathrm{S}$, Mises $(\mathrm{MPa})$

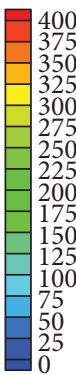

Case a19: $E_{s}=100 \mathrm{GPa}, \mu_{\mathrm{s}}=0.2$.

FIGURE 3: Mises stress distribution and monitor point positions of typical cases. 
TABle 4: Mises stress difference for interface.

\begin{tabular}{|c|c|c|c|c|c|c|}
\hline Case & Interface & Point 1 & Mises stress $1(\mathrm{MPa})$ & Point 2 & Mises stress $2(\mathrm{MPa})$ & Stress difference $(\mathrm{MPa})$ \\
\hline \multirow{10}{*}{ a1 } & \multirow{5}{*}{ Vertical face } & V11 & 47.308 & V21 & 35.089 & 12.219 \\
\hline & & V12 & 36.909 & V22 & 32.581 & $4.328 \downarrow$ \\
\hline & & V13 & 44.173 & V23 & 29.035 & $15.138 \uparrow$ \\
\hline & & V14 & 107.237 & V24 & 38.401 & 68.836 \\
\hline & & V15 & 194.566 & V25 & 74.681 & 119.885 \\
\hline & \multirow{5}{*}{ Horizontal face } & $\mathrm{H} 11$ & 269.114 & $\mathrm{H} 21$ & 57.006 & 212.109 \\
\hline & & $\mathrm{H} 12$ & 203.616 & $\mathrm{H} 22$ & 59.392 & 144.224 \\
\hline & & $\mathrm{H} 13$ & 139.720 & $\mathrm{H} 23$ & 66.652 & 73.068 \\
\hline & & H14 & 111.393 & $\mathrm{H} 24$ & 90.475 & 20.918 \\
\hline & & H15 & 188.662 & $\mathrm{H} 25$ & 134.802 & $53.860 \uparrow$ \\
\hline \multirow{10}{*}{ a14 } & \multirow{5}{*}{ Vertical face } & V11 & 18.991 & V21 & 12.434 & 6.557 \\
\hline & & V12 & 28.005 & $\mathrm{~V} 22$ & 20.834 & 7.171 \\
\hline & & V13 & 45.095 & V23 & 33.645 & 11.450 \\
\hline & & V14 & 75.659 & V24 & 52.698 & 22.961 \\
\hline & & V15 & 124.927 & V25 & 106.439 & $18.488 \downarrow$ \\
\hline & \multirow{5}{*}{ Horizontal face } & H11 & 163.602 & $\mathrm{H} 21$ & 103.427 & 60.175 \\
\hline & & $\mathrm{H} 12$ & 117.762 & $\mathrm{H} 22$ & 89.125 & 28.637 \\
\hline & & $\mathrm{H} 13$ & 78.770 & $\mathrm{H} 23$ & 76.849 & 1.921 \\
\hline & & $\mathrm{H} 14$ & 79.559 & $\mathrm{H} 24$ & 79.814 & -0.255 \\
\hline & & H15 & 106.298 & $\mathrm{H} 25$ & 107.846 & -1.548 \\
\hline \multirow{10}{*}{ a19 } & \multirow{5}{*}{ Vertical face } & V11 & 17.054 & $\mathrm{~V} 21$ & 10.097 & 6.958 \\
\hline & & $\mathrm{V} 12$ & 29.651 & V22 & 21.459 & $8.1924 \uparrow$ \\
\hline & & V13 & 42.620 & V23 & 36.959 & $5.661 \downarrow$ \\
\hline & & V14 & 61.786 & V24 & 54.905 & $6.881 \uparrow$ \\
\hline & & V15 & 97.813 & V25 & 98.184 & $-0.371 \downarrow$ \\
\hline & \multirow{5}{*}{ Horizontal face } & H11 & 159.945 & $\mathrm{H} 21$ & 113.038 & 46.907 \\
\hline & & H12 & 115.197 & $\mathrm{H} 22$ & 94.686 & 20.511 \\
\hline & & H13 & 75.231 & $\mathrm{H} 23$ & 76.929 & -1.698 \\
\hline & & H14 & 70.179 & $\mathrm{H} 24$ & 75.810 & -5.631 \\
\hline & & H15 & 85.837 & $\mathrm{H} 25$ & 100.116 & -14.279 \\
\hline
\end{tabular}

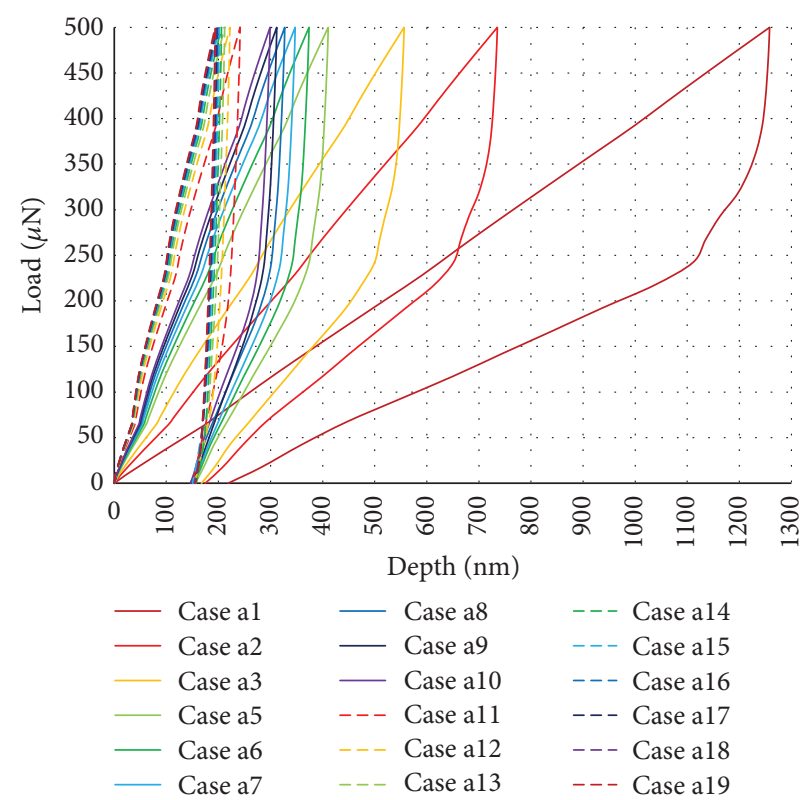

FIgure 4: The load-depth curves of series 1. 


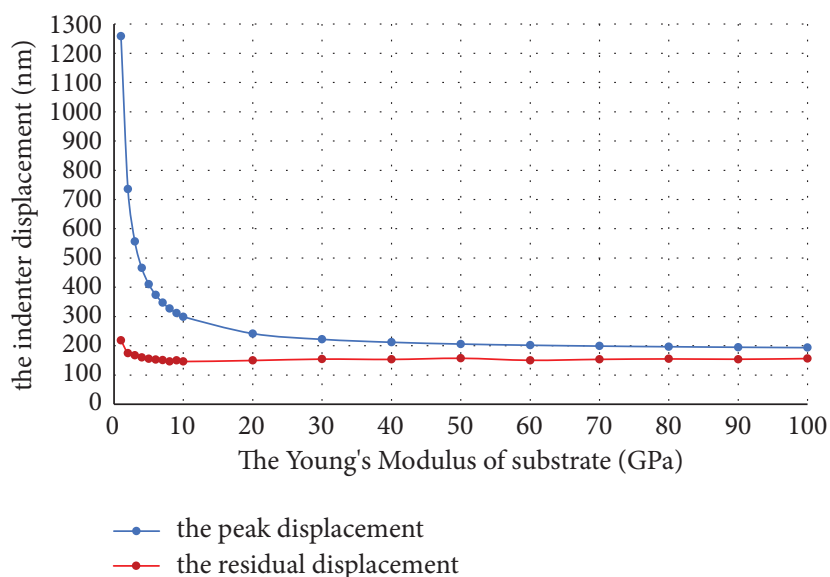

Figure 5: The relationship between displacement and $E_{s}$.
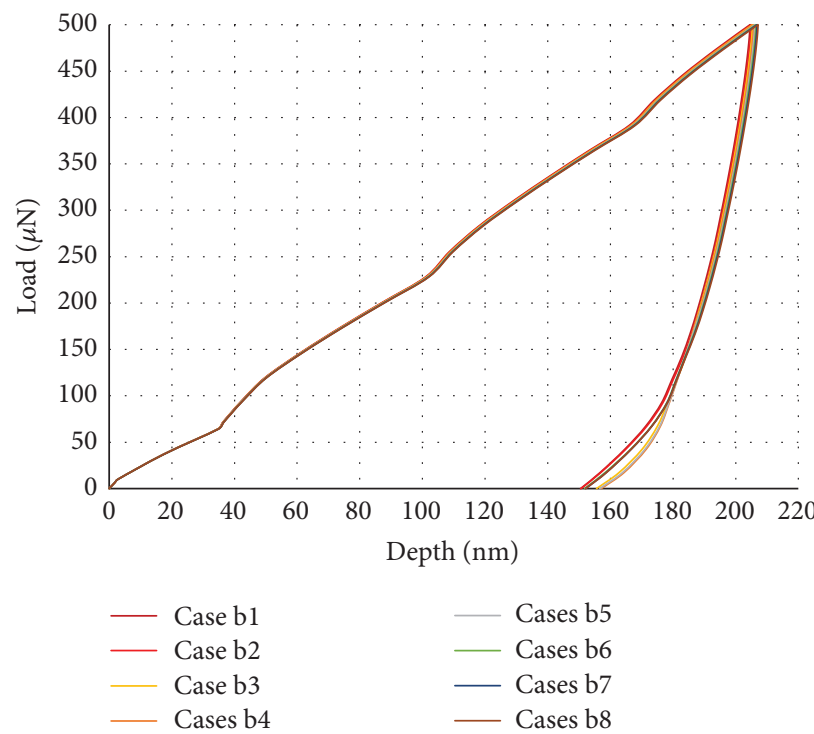

Figure 6: The load-depth curves of series 2.

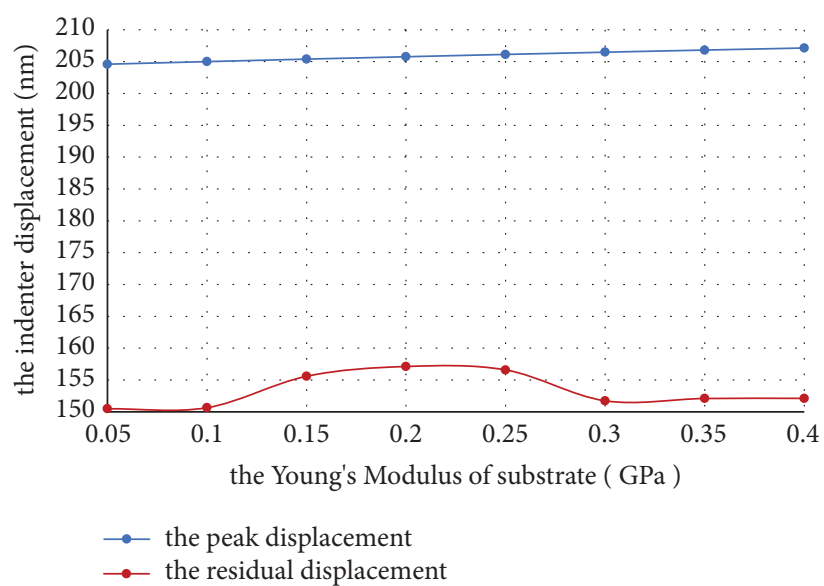

Figure 7: The relationship between displacement and $\mu_{s}$. 


\section{Conclusion}

In this paper, a NI experiment was introduced firstly; this experiment shows the substrate effect in the hybrid material. Then the series of numerical experiments were carried out to explore the substrate effect in the nanoindentation experiment of the hybrid material. The results shows that the numerical experiments present are consistent with experiments. The following are mainly conclusions obtained in this paper.

It was a clear difference of the NI experiment result between the coating/substrate combination and hybrid material under the same experiment condition. The difference is mainly derived from two factors: the lateral stiffness and the discontinuous face. In the coating/substrate model, the lateral stress is actually provided by the coating material in which the mechanical property is identical, whereas the substrate material offers the lateral boundary in the hybrid material model. When Young's modulus of substrate $E_{s}$ is greater than the testing material, the boundary would be "harder," and the indenter displacement would be smaller correspondingly.

The influence of the discontinuous interface between the testing area and the substrate was also observed through the stress contour. The discontinuous face could distinctly weaken the stress transfer; that is, the Mises stress of the testing material is generally greater than the neighbor point in the substrate. The discontinuous face also causes stress concentration, which always occurs near the bottom corner of the testing material where two interfaces are intersected. Furthermore, the stress difference of the interface generally gradually decreases in the horizontal direction, whereas it fluctuates in the vertical direction, excluding the area of stress concentration.

Detailed parametric studies regarding Young's modulus $E_{s}$ and Poisson's ratio $\mu_{s}$ of the substrate were conducted. Based on the results, Young's modulus of the substrate $E_{s}$ has a substantial influence on the NI experiment. In general, the indenter peak displacement $h_{\text {peak }}$ decreases with $E_{s}$ increasing, but the decreasing rate is different. When $E_{s}$ is small, less than $10 \mathrm{GPa}$ in this paper, $h_{\text {peak }}$ descends rapidly. When $E_{s}$ further increases, $h_{\text {peak }}$ curve gradually tends to flat.

As $E_{s}$ is less than $8 \mathrm{GPa}$, the residual displacement $h_{\text {residual }}$ decreases along with the substrate Young's modulus increasing, similar to $h_{\text {peak }}$, but reduced value is only $72.01 \mathrm{~nm}$, which is far less than the $h_{\text {peak }}$ change. As $E_{s}$ further increased, the curve starts to increase in fluctuation, but the increment is very small.

It could be concluded that the NI experiment result is more sensitive to smaller $E_{s}$, including $h_{\text {peak }}$ and $h_{\text {residual }}$.

Comparatively, Poisson's ration of substrate $\mu_{s}$ has less impact on the NI experiment. $h_{\text {peak }}$ and $h_{\text {residual }}$ only vary in $5 \mathrm{~nm}$ when $\mu_{s}$ increases from 0.05 to 0.4 . By further analysis, $h_{\text {peak }}$ is positively associated with $\mu_{s}$, but there is no obvious correlation between $h_{\text {residual }}$ and $\mu_{s}$. The closer $\mu_{s}$ is to the testing materials, the greater $h_{\text {residual }}$ is. When $\mu_{s}$ is equal to the testing materials, $h_{\text {residual }}$ reaches its maximum value.

\section{Data Availability}

The data used in this study have been already posted in this paper.

\section{Conflicts of Interest}

The authors declare that there are no conflicts of interest regarding the publication of this study.

\section{References}

[1] P. Zhan, J. Xu, J. Wang, and C. Jiang, "Multi-scale study on synergistic effect of cement replacement by metakaolin and typical supplementary cementitious materials on properties of ultra-high performance concrete," Construction and Building Materials, vol. 307, Article ID 125082, 2021.

[2] F. M. Borodich, L. M. Keer, and C. S. Korach, "Analytical study of fundamental nanoindentation test relations for indenters of non-ideal shapes," Nanotechnology, vol. 14, no. 7, pp. 803-808, 2003.

[3] J. Chen and S. J. Bull, "On the factors affecting the critical indenter penetration for measurement of coating hardness," Vacuum, vol. 83, no. 6, pp. 911-920, 2009.

[4] Y. H. Lee, J. H. Hahn, S. H. Nahm, J. I. Jang, and D. Kwon, "Investigations on indentation size effects using a pile-up corrected hardness," Journal of Physics D: Applied Physics, vol. 41, no. 7, Article ID 074027, 2008.

[5] M. Zhao, X. Chen, N. Ogasawara et al., "New sharp indentation method of measuring the elastic-plastic properties of compliant and soft materials using the substrate effect," Journal of Materials Research, vol. 21, no. 12, pp. 3134-3151, 2006.

[6] J. Xu, D. J. Corr, and S. P. Shah, "Nanomechanical investigation of the effects of nanoSiO2 on C-S-H gel/cement grain interfaces," Cement and Concrete Composites, vol. 61, pp. 7-17, 2015.

[7] J. Xu, B. Wang, and J. Zuo, "Modification effects of nanosilica on the interfacial transition zone in concrete: a multiscale approach," Cement and Concrete Composites, vol. 81, pp. 1-10, 2017.

[8] J. Xu, Y. Tang, X. Wang, Z. Wang, and W. Yao, “Application of ureolysis-based microbial $\mathrm{CaCO} 3$ precipitation in selfhealing of concrete and inhibition of reinforcement corrosion," Construction and Building Materials, vol. 265, Article ID 120364, 2020.

[9] X. Wu, S. S. Amin, and T. T. Xu, "Substrate effect on the Young's modulus measurement of $\mathrm{TiO} 2$ nanoribbons by nanoindentation," Journal of Materials Research, vol. 25, no. 5, pp. 935-942, 2010.

[10] M. Zhao, X. Chen, Y. Xiang et al., "Measuring elastoplastic properties of thin films on an elastic substrate using sharp indentation," Acta Materialia, vol. 55, no. 18, pp. 6260-6274, 2007.

[11] Y. Liao, Y. Zhou, Y. Huang, and L. Jiang, "Measuring elasticplastic properties of thin films on elastic-plastic substrates by sharp indentation," Mechanics of Materials, vol. 41, no. 3, pp. 308-318, 2009.

[12] M. N. Zulkifli, A. Jalar, S. Abdullah, I. A. Rahman, and N. K. Othman, "Effect of applied load in the nanoindentation 
of gold ball bonds," Journal of Electronic Materials, vol. 42, no. 6, pp. 1063-1072, 2013.

[13] T. Csanádi, D. Németh, and F. Lofaj, "Mechanical properties of hard W-C coating on steel substrate deduced from nanoindentation and finite element modeling," Experimental Mechanics, vol. 57, no. 7, pp. 1057-1069, 2017.

[14] N. Fujisawa, T. F. Zhang, O. L. Li, and K. H. Kim, "Substrateindependent stress-strain behavior of diamond-like carbon thin films by nanoindentation with a spherical tip," Journal of Materials Research, vol. 33, no. 6, pp. 699-708, 2018.

[15] C. Gamonpilas and E. P. Busso, "On the effect of substrate properties on the indentation behaviour of coated systems," Materials Science and Engineering: A, vol. 380, no. 1-2, pp. 52-61, 2004.

[16] R. Saha and W. D. Nix, "Effects of the substrate on the determination of thin film mechanical properties by nanoindentation," Acta Materialia, vol. 50, no. 1, pp. 23-38, 2002.

[17] X. Xing, Y. Wang, G. Xiao, X. Shu, S. Yu, and Y. Wu, "Identifying the elastoplastic properties of ductile film on hard substrate by nanoindentation," Vacuum, vol. 189, Article ID 110252, 2021.

[18] I. A. Lyashenko and V. L. Popov, "The effect of contact duration and indentation depth on adhesion strength: experiment and numerical simulation," Technical Physics, vol. 65 , no. 10 , pp. 1695-1707, 2020.

[19] W.-G. Jiang, J.-J. Su, and X.-Q. Feng, "Effect of surface roughness on nanoindentation test of thin films," Engineering Fracture Mechanics, vol. 75, no. 17, pp. 4965-4972, 2008.

[20] M. Li, H.-X. Zhang, Z.-L. Zhao, and X.-Q. Feng, "Surface effects on cylindrical indentation of a soft layer on a rigid substrate," Acta Mechanica Sinica, vol. 36, no. 2, pp. 422-429, 2020.

[21] J. Malzbender, G. de With, and J. den Toonder, "The P-h2 relationship in indentation," Journal of Materials Research, vol. 15, no. 5, pp. 1209-1212, 2000.

[22] J. Malzbender and G. de With, "Indentation load-displacement curve, plastic deformation, and energy," Journal of Materials Research, vol. 17, no. 2, pp. 502-511, 2002.

[23] L. Min, C. Wei-min, L. Nai-gang, and W. Ling-Dong, "A numerical study of indentation using indenters of different geometry," Journal of Materials Research, vol. 19, no. 1, pp. 73-78, 2004.

[24] F. Lofaj and D. Németh, "The effects of tip sharpness and coating thickness on nanoindentation measurements in hard coatings on softer substrates by FEM," Thin Solid Films, vol. 644, pp. 173-181, 2017. 